Three-dimensional numerical modelling of ballasted railway track foundations for high-speed trains with special reference to critical speed

\author{
Md. Abu Sayeed* \\ PhD Candidate, Department of Civil Engineering, \\ Curtin University, WA 6845, Australia \\ Mobile: +61404214238 \\ E-mail: sayeed.ce00@yahoo.com
}

\author{
Mohamed A. Shahin \\ Associate Professor, Department of Civil Engineering, \\ Curtin University, WA 6845, Australia \\ Phone: +61-8-9266 1822; Fax: +61-8-9266 2681 \\ E-mail: M.Shahin@curtin.edu.au
}

*Corresponding author

SUBMITTED TO: TRANSPORTATION GEOTECHNICS 


\title{
Three-dimensional numerical modelling of ballasted railway track foundations for high- speed trains with special reference to critical speed
}

Md. Abu Sayeed ${ }^{\mathrm{a} * *}$ and Mohamed A. Shahin ${ }^{\mathrm{b}}$

${ }^{a}$ PhD Candidate, Department of Civil Engineering, Curtin University, WA 6845, Australia

${ }^{b}$ Assoc. Professor, Department of Civil Engineering, Curtin University, WA 6845, Australia

\begin{abstract}
Due to recent congestion of highways in many countries around the world, railways have become the most popular means of public transportation, which has increased the demand for heavier and faster trains. High speeds and heavy loads of trains are usually accompanied with large vibrations in the train-track-ground system, especially when train speed reaches its critical value, leading to possible train derailment and track damages. This unwanted scenario makes it important for railway geotechnical engineers to investigate the behaviour of ballasted railway track foundations for high-speed trains, with special reference to critical speed. In the current paper, a sophisticated three-dimensional (3D) finite element (FE) modelling was developed to simulate the dynamic response of ballasted railway tracks subjected to train moving loads, and the critical speed was investigated for various traintrack-ground system conditions. The results were presented in terms of the evolution of the coefficient of dynamic amplification of sleeper deflection versus train speed, which have been synthesized into simple sensitivity charts that can be used to determine the critical speed corresponding to the conditions of a particular train-track-ground system.
\end{abstract}

Keywords: Ballasted railway tracks; High-speed trains; Critical speed; Finite element modelling; Train moving loads.

\footnotetext{
* Corresponding authors. Email address: sayeed.ce00@yahoo.com (M. A. Sayeed).
} 


\section{Introduction}

The development of high-speed train (HST) networks is rapidly growing in many countries around the world to meet the increasing demand for faster transportation. For instance, the Japanese railways authority constructed the HST $4072 \mathrm{~km}$ long Shinkansen network for trains running at a speed of $320 \mathrm{~km} / \mathrm{h}$. Recently, using the magnetic levitation technology, the Japanese bullet train broke the world train speed record in a test conducted in 2015 for a train running at a blazing speed of $603 \mathrm{~km} / \mathrm{h}$ (Wener-Fligner, April 21, 2015). On the other hand, China has the world largest HST network which is about 16,000 km long, and the Chinese railway authority expects that the train speeds in China will increase to up to $400 \mathrm{~km} / \mathrm{h}$ in the near future. As train speeds continue to increase, new challenges and problems relating to the performance of railway foundations may arise, primarily due to the significant amplification effect of the train-track-ground vibration (Priest and Powrie, 2009; Wanming et al., 2010). The train-induced ground vibration is dictated mostly by the relationship between the train speed and the corresponding propagating wave velocity of the ground medium. The train speed at which the dynamic response of railway track and surrounding ground are intensely amplified and extraordinary large vibration occurs due to resonance is called the "critical speed' (Krylov, 1994; Madshus and Kaynia, 1999; Yang et al., 2009). The tremendous increase of the vibration level associated with the critical speed is not only a possible source of detrimental environmental effect and human disturbance, but can also increase the risk of several train operation issues. These include the train safety, degradation/deformation of track foundations, fatigue failure of rails and interruption of power supply to trains (Madshus and Kaynia, 2000). 
The adverse impact of high speed of trains invoked a flurry of research activities as manifested in the experience of the Swedish Rail Administration (SRA). In 1997, SRA (Banverket) started running the X-2000 passenger HST along the West Coast Line between Göteborg and Malmö. Just after commencing the service, excessive vibrations in the railway embankment and the surrounding soil were observed at the Ledsgard site (where the railway track was founded on soft soils). Inspection of the track revealed that the train speed approached the critical value (Woldringh and New, 1999), and the train speed was immediately reduced by the SRA authority as a consequence. This incident highlighted problems ensuing from the critical speed. Due to the practical significance of this matter, several efforts (e.g. Madshus and Kaynia, 1999; Kaynia et al., 2000) were made to understand the track responses and determine the optimum running speed of the X-2000 HST at the Ledsgard site using different empirical methods. Subsequent to this case study and long after, several analytical and numerical approaches were proposed by a number of researchers to assess the critical speed and associated issues (e.g. Grundmann et al., 1999; Sheng et al., 2004; Bian and Chen, 2006; Auersch, 2008; Bian et al., 2014; Alves Costa et al., 2015). However, to assess the critical speed of the train-track-ground system, most of the abovementioned studies considered cyclic loading or single wheel (or surface) moving load rather than true (dynamic) train moving loads. The drawback of this assumption is that it does not consider the role of the principal stress rotation on behaviour of soil (Powrie et al., 2007; Powrie et al., 2008). In addition, the consideration of a single wheel moving load is highly arguable as the actual loading regime of a running train is characterised by a series of wheel loads with different amplitudes and geometry (hence the role of frequency). These loading conditions are expected to produce critical speed conditions that are considerably different from those obtained from a monotonic or cyclic loading regime. Therefore, the actual train 
geometry and magnitude of individual axle load need to be accounted for in the analysis considering the critical speed, which will be the case in the current presented work.

In the current study, an advanced three-dimensional (3D) finite element (FE) numerical modelling is developed to simulate the dynamic response of railway track foundations under true train moving loads, with special reference to the critical speed. Various conditions of the train-track-ground system affecting the critical speed are investigated, including the nonlinearity of track material, modulus and thickness of track subgrade soil, amplitude of train loading and train geometry. The obtained results are synthesized into simple sensitivity charts from which the critical speed under various conditions of the train-track-ground system can be readily obtained. The paper also discusses the practical implications of the obtained outcomes on track design.

\section{Numerical modelling of railway track foundation system}

In this section, the dynamic response of railway track foundations subjected to train moving loads was investigated via 3D FE numerical modelling using the commercial software package Midas-GTS (MIDAS IT. Co. Ltd., 2013). It should be noted that the thrust of the numerical modelling performed in this study has been to investigate and produce sensitivity charts for the critical speed of trains under various conditions of the train-track-ground system. Therefore, it was critically prudent to ensure that the FE modelling process is capable of providing reliable outcomes. To this end, it was decided to perform an initial analysis on a case study that is well documented in the literature to ascertain that the model can reproduce field results of compiled measurements obtained from this case study. Then for the sake of simplicity and ease of simulation, another track with simplified substructure than that of the 
case study was adopted to investigate the critical speed and produce the sensitivity charts, as will be seen below.

\subsection{Modelling of the X-2000 HST railway track at the Ledsgard site}

The selected case study for initial analysis of the numerical modelling was for a ballasted railway track of the X-2000 HST at Ledsgard site just outside Göteborg (Hall, 2003). This case study was selected because it contains detailed description of all track components and material properties needed for the FE modelling, as well as field measurements of the track and ground vibration parameters.

\subsubsection{Track geometry and materials}

The geometry and subgrade profile of the X-2000 HST railway track at the Ledsgard site (Hall, 2003) are shown in Fig. 1a, whereas the 3D FE model developed to simulate the problem is depicted in Fig. 1b. The model dimensions are $80 \mathrm{~m}, 36 \mathrm{~m}$ and $12 \mathrm{~m}$ in the longitudinal, horizontal and vertical directions, respectively. The rail was modelled using

one-dimensional (1D) I-beam section running across the length of the modelled track. A UIC60 section was assumed for the rail, which was fixed to the sleepers by rail pads characterized by an elastic link (spring-like) element of stiffness equal to $100 \mathrm{MN} / \mathrm{m}$. All other track components (i.e. sleeper, ballast, interface and subgrade) were modelled using 3D solid elements. For model geometry, a total of 133 sleepers were placed along the rail at $0.6 \mathrm{~m}$ interval spacing. The rail and sleepers were considered as linear elastic (LE) materials, whereas the ballast and interface layer were modelled using elastoplastic Mohr-Coulomb (MC) materials. The subgrade (formation) soils (see Fig. 1a) were modelled using nonlinear 
materials in which the nonlinearity was taken into account via an equivalent linear material in accordance with the approach described by Madshus and Kaynia (1999). The properties of all materials considered for this model are summarized in Table 1.

In any dynamic analysis, the finite element size, model boundaries and time step have to be selected carefully to ensure the accuracy of results (Galavi and Brinkgreve, 2014). In general, the element size of the FE model was estimated based on the smallest wavelength that allows the high-frequency motion to be simulated correctly. Accordingly, the sizes of used 3D finite elements were taken as: $0.167 \mathrm{~m} \times 0.137 \mathrm{~m} \times 0.2 \mathrm{~m} ; 0.2 \mathrm{~m} \times 0.2 \mathrm{~m} \times 0.2 \mathrm{~m}$; and $0.6 \mathrm{~m} \times 0.6$ $\mathrm{m} \times 0.6 \mathrm{~m}$ for the sleepers, ballast and subgrade, respectively. Hence, the mesh of the FE model for the X-2000 HST railway track consisted of 285,000 elements. The model vertical boundaries were connected to viscous dampers to absorb the incident $S$ - and $P$ - waves and to represent infinite boundary conditions (Lysmer and Kuhlemeyer, 1969; Kouroussis et al., 2011). The nodes at the bottom boundary were set to be fixed in every direction to simulate bedrock. The material damping of the FE model was characterized by the mass and stiffness proportional coefficients, normally referred to as the Rayleigh damping, which is commonly used in nonlinear dynamic analyses. The generalized equation for the Rayleigh damping is as follows:

$[C]=\alpha[M]+\beta[K]$

where: $[C]$ is the damping matrix; $[M]$ is the mass matrix; and $[K]$ is the stiffness matrix. The parameters $\alpha$ and $\beta$ are the mass and stiffness proportional damping coefficients, respectively. These damping coefficients are frequency-dependent and can be computed using the following equations (Chowdhury and Dasgupta, 2003): 
$\alpha=\frac{2 \omega_{i} \omega_{j}\left(\xi_{i} \cdot \omega_{j}-\xi_{j} \cdot \omega_{i}\right)}{\omega_{j}^{2}-\omega_{i}^{2}}$

$\beta=\frac{2\left(\xi_{j} . \omega_{j}-\xi_{i} . \omega_{i}\right)}{\omega_{j}^{2}-\omega_{i}^{2}}$

where: $\omega_{i}$ and $\omega_{j}$ are the natural frequency of mode- 1 and mode- 2 of the full model, respectively, for which the effective modal mass participation factors are high in the loading direction; and $\xi_{i}$ and $\xi_{j}$ are the hysteretic material damping ratios in the frequency range of interest (see Table 1). It should be noted that the natural frequency mode of the FE model was obtained by an eigenvalue analysis considering the subgrade reaction at the boundary of the layered material mesh using Midas-GTS software.

\subsubsection{Simulation of train moving loads}

The train geometry and standard axle loads of the X-2000 HST used in the FE modelling are summarized in Table 2, which include (for each car number) the distance between the axles (a), distance between two bogies $(b)$, carriage length $(L)$ and total axle weight of each carriage $(P)$. Fig. 2a shows a schematic diagram of the X-2000 HST showing its components, whereas Fig. 2b depicts the Thalys HST which will be studied later.

In the current study, the train moving loads were modelled in accordance with Araújo (2011) in which the rail FE nodes, which are rigidly connected to the sleepers via pads, were subjected to a wheel load (denoted as loading nodes) whose value changes in time (note that the spacing between any two loading nodes is $0.6 \mathrm{~m}$ ). As schematically shown in Fig. 3, the 
train moving loads can be thought of as triangular pulses distributed among three nodes. The wheel load, $F$, at one certain loading node, $N+1$, increases once the wheel leaves node $N$, reaching a peak value when the wheel is directly above node $N+1$, then finally decreasing back to zero when the wheel reaches the next node $N+2$. As a result, the triangular pulse moves from one node to another by a time interval equal to the spacing of the loading nodes divided by the speed, $C$, of the moving loads. In this fashion, a series of train wheels was considered to be moving along the track. During the simulation of moving loads, the time $\underline{\text { step was chosen based on the well-known Courant-Friedrichs-Lewy condition which is }}$ mathematically represented as follows (Galavi and Brinkgreve, 2014):

$$
C_{n}=\frac{\Delta t \times c}{L_{\min }} \leq 1
$$

where: $C_{n}$ is called the Courant number, $\Delta t$ is the time step, $C$ is the train speed and $L_{\min }$ is distance between two adjacent loading nodes.

In the current study, all FE analyses were performed in the time domain, which is more natural to reproduce the transient phenomenon of wave propagation (Kouroussis et al., 2009).

\subsubsection{Validation of $3 D$ modelling of the $X-2000$ HST railway track}

To validate the FE modelling of the X-2000 HST railway track set out above, the time-history response of the sleeper deflection during the passage of train at three different speeds of 70 , 200 and $252 \mathrm{~km} / \mathrm{h}$ was calculated at the centre of track. The results were then compared with the corresponding field measurements as well as simulated response reported by Kaynia et al. (2000), as shown in Fig. 4 (the upward and downward deflections are presented by positive 
and negative values, respectively). It can be seen that for low speed of $70 \mathrm{~km} / \mathrm{h}$ (Fig. 4a), only quasi-static deflection (i.e. downward movement) appears when the load moves over the point of concern. In contrast, an oscillatory response (see Fig. 4b \& c) is occurred at higher speed of 200 and $252 \mathrm{~km} / \mathrm{h}$. For all train speeds, it is clearly shown that the FE predictions agree reasonably well with the field measurements and previous published simulated response.

As an additional validation tool, the vertical track deflections were reproduced in the frequency domain, using Fourier transformation via Matlab, and the results of this exercise were judged against the frequency domain deflection obtained from the field measurements, as shown in Fig. 5. It can be clearly seen that good agreement exists between the FE predictions and field measurements, for both the low speed (Fig. 5a) and high speed (Fig. 5b). The overall agreement between the numerical and measured deflections confirms that the FE modelling process adopted in this study is reliable and can be used with confidence to predict the railway track behaviour, for both the quasi-static and dynamic loading conditions.

\subsection{Investigation into critical speed of train-track-ground system}

As mentioned earlier, when the train speed reaches the critical speed of the train-track-ground system, extraordinary large vibrations occur, leading to possible track damages and train derailment. To avoid this undesirable scenario, an investigation that aims at determining the influence of various conditions of the train-track-ground system on the critical speed is essential for Railway Geotechnical engineers. These various conditions include the nonlinearity of track materials, stiffness and thickness of track subgrade, amplitude of train loading and geometry of train loading, as will be presented in some detail next. For this 
purpose, a FE model similar to that developed earlier for the X-2000 HST but with a simpler profile was used (see Fig. 6), which consists a ballast layer of $0.35 \mathrm{~m}$ founded on a single subgrade layer of $7.5 \mathrm{~m}$, overlying a hard bedrock.

\subsubsection{Effect of nonlinearity of track materials}

The impact of nonlinearity of track materials on the critical speed was investigated separately for two different subgrades, one with soft soil (i.e. fat clay of the Monroe dam) and the other with stiff soil (i.e. low density sand). Each type of subgrade soil was modelled for two different scenarios (i.e. linear and non-linear). In the first scenario, the subgrade material (i.e. clay or sand) and ballast were represented by a linear elastic material, whereas in the second scenario the subgrade soil was modelled using the hyperbolic Duncan-Chang (DC) constitutive model (Duncan and Chang, 1970) whilst the ballast was simulated by the elastoplastic Mohr-Coulomb (MC) model. Accordingly, a total of four models were considered; a summary of which is presented in Table 3 and the properties of all track materials are summarized in Table 4. It should be noted that the ballast properties provided in Table 4 were obtained from Anderson and Fair (2008), whereas the subgrade used was assumed as fat clay of the Monroe dam and its properties were obtained from Duncan et al. (1980). On the other hand, the sand subgrade properties were obtained from Al-Shayea et al. (2003). These materials are assumed to be typical of soft and stiff subgrades.

Fig. 7 shows the sleeper downward and upward deflections versus train speed, for both subgrades used (i.e. Fig. 7a for soft subgrade and Fig. $7 \mathrm{~b}$ for stiff subgrade). It can be seen that the sleeper deflection generally increases with the increase of train speed, reaching its maximum value at the critical speed, before it decreases with the further increase of train 
speed. Fig. 7 clearly demonstrates that the upward movement profile is insensitive to subgrade nonlinearity. In general, subgrade nonlinearity resulted in higher downward movement than that of linear subgrade; however, the difference is relatively small in the case of stiff subgrade compared to soft subgrade, which is obvious as soft materials usually show higher nonlinearity than stiff materials. Fortunately, the difference in magnitude of the critical speed between the linear and nonlinear subgrade tracks is almost negligible, for both the soft and stiff subgrades. Consequently, it was decided that the remaining part of the current study to be conducted only on linear track materials.

For illustration purpose of the impact of critical speed on the track compared to the lower speed, contour plots of obtained vertical deflections along the track for Model-3 (i.e. linear stiff subgrade track) are depicted in Fig. 8 at the critical speed and at a speed lower than the critical speed. It can be seen from Fig. 8a that at train speed of $50 \mathrm{~m} / \mathrm{s}$, which is lower than the critical speed, the vertical deflection is mainly induced near the axle positions and there is a slight propagation of wave to the surrounding ground, as expected. On the contrary, it can be seen from Fig. $8 \mathrm{~b}$ that at the critical speed of $185 \mathrm{~m} / \mathrm{s}$, the vertical deflection is not only induced near the axle positions but also in the surrounding ground. It can also be seen that a series of wave fronts radiating from the load positions showing a shockwave in the ground which is known as the Mach cone is formed; this phenomenon is similar to the case of sonic boom normally associated with supersonic aircraft (Krylov, 2001). This result confirms that the FE modelling is trustworthy and can be used with confidence to predict the railway track behaviour at the critical speed or otherwise.

Apart from the effect of track nonlinearity discussed above on train critical speed, two important aspects warrant discussion for the results presented in Fig. 7. Firstly, the critical 
speed determined for either case of soft or stiff subgrade is actually higher than both the Rayleigh wave and shear wave velocities of the subgrade (i.e. the critical speed $\approx 65 \mathrm{~m} / \mathrm{s}$ versus $C_{R}=37 \mathrm{~m} / \mathrm{s}$ and $C_{s}=40 \mathrm{~m} / \mathrm{s}$ for track with soft subgrade; whereas the critical speed $\approx$ $185 \mathrm{~m} / \mathrm{s}$ versus $C_{R}=109 \mathrm{~m} / \mathrm{s}$ and $C_{s}=117 \mathrm{~m} / \mathrm{s}$ for track with stiff subgrade). This suggests that the critical speed is not always equal to the Rayleigh wave velocity of the top subgrade medium as sometimes thought, and this can be attributed to the existence of the bottom hard bedrock as well as the ballast layer that acts as a beam, as suggested by Bian et al. (2014) and Alves Costa et al. (2015). Secondly, by analysing the results presented in Fig. 7, it can be seen that in both soft and stiff subgrade tracks, the sleeper deflections are almost constant for train speed lower than $30 \%$ of the critical speed and the dynamic effects commence after that level of train speed. However, the sleeper deflection increases sharply when the train speed passes around $75 \%$ of the critical speed and maintains the same trend until it reaches the critical speed. Therefore, based on the above results, $75 \%$ of the critical speed value can be assumed as the practical speed limit for ballasted railway tracks.

\subsubsection{Effect of stiffness and thickness of track subgrade}

As the propagation wave velocity of any soil medium is highly dependent on its stiffness and thickness (Alves Costa et al., 2015), the effects of the top subgrade stiffness (or soil modulus), $E_{s}$, and thickness, $H_{s}$, on the critical speed of train-track-ground system need to be investigated. It is well known that the influence of critical speed is more significant for reduced subgrade stiffness, which means that tracks built on soft subgrade usually yield high ground vibrations at low train speed than those founded on stiff subgrade. To investigate the impact of the subgrade stiffness on the critical speed, five different values of subgrade modulus were considered $\left(E_{s}=7.5,15,30,60\right.$, and $\left.120 \mathrm{MPa}\right)$. Similarly, the impact of the 
subgrade thickness was investigated by considering four different subgrade thicknesses $\left(H_{s}=\right.$ $B, 1.5 B, 2 B$ and $\infty$ ), where $B$ is the bottom width of the track embankment overlying the subgrade, as shown in Fig. 6.

The impact of track subgrade stiffness and thickness is presented in Fig. 9, in terms of the relationship between the normalized train speed $\left(C / C_{R}\right)$ and dynamic amplification factor (DAF). The DAF is defined as the ratio of the maximum dynamic sleeper deflection at a particular train speed to the maximum quasi-static sleeper deflection (i.e. at a nominal train speed of $5 \mathrm{~m} / \mathrm{s}$ ). It can be seen from Fig. 9 that, for all values of $E_{s}$ and $H_{s}$, the DAF increases with the increase of the train speed until it reaches a peak value corresponding to the critical speed, after which it decreases with further increase in the train speed. Fig. 9(a) shows that, while the critical speed increases proportionally with the increase in the track subgrade stiffness (i.e., Rayleigh wave velocity), the DAF exhibits an opposite effect. The practical implication of this finding is that the localised ground improvements to spots of soft soil along the rail track can be very beneficial in increasing the critical speed of trains. Fig. 9(b) shows that the magnitude of the critical speed increases with the decrease in the track subgrade thickness. It can also be seen that the critical speed determined for each subgrade thickness is higher than the Rayleigh wave and shear wave velocities of the top subgrade soil overlying the hard bedrock. This result is consistent with the findings reported by Alves Costa et al. (2015).

\subsubsection{Effect of amplitude of train moving loads}

The influence of amplitude of train moving loads on the critical speed was investigated using three different loading values denoted herein as standard, light and heavy. The standard 
loading was considered to be equivalent to the axle loads given in Table 2, whereas the light loading was $25 \%$ less than the standard loading and the heavy loading was $25 \%$ higher than the standard loading. The track investigated was similar in geometry to that shown in Fig. 6 with stiff subgrade properties as given in Table 4 (i.e. Model-3). The relationship between the sleeper deflection and train speed for the three loading amplitudes considered is shown in Fig. 10. As expected, the sleeper deflection increases with increasing the loading amplitude for all speeds. On the other hand, it can also be seen that the critical speed is almost the same regardless of the train loading amplitude, implying that he critical speed is not affected by the magnitude of train loading.

\subsubsection{Effect of geometry of train loading}

The effect of geometry of the train loading regime on the critical speed is important for railway transport authorities since it can guide to choice of a suitable train for a particular track-ground condition. In this part, the influence of geometry of train loading on the critical speed was investigated by considering two trains of different loading geometries, i.e. the $\mathrm{X}$ 2000 HST and Thalys HST (see Fig. 2 earlier). The geometry and loading characteristics of the X-2000 HST are previously shown in Table 2, whereas the geometry and loading characteristics of the Thalys HST are given in Table 5, which includes (Degrande and Schillemans, 2001): the carriage length $(L)$, distance between two bogies $\left(L_{b}\right)$, distance between two axles of bogie $\left(L_{a}\right)$ and total axle load of each carriage $\left(W_{t}\right)$. Again, a track similar to that shown in Fig. 6 was used with stiff subgrade properties given in Table 4 (i.e. Model-3). The results are shown in Fig. 11 in terms of the evolution of the DAF of sleeper deflection with train speed. It can be seen that both the maximum DAF and corresponding critical speed for the two trains are different. The critical speed obtained for the Thalys HST 
and the X-2000 HST were found to be equal to $142 \mathrm{~m} / \mathrm{s}$ and $185 \mathrm{~m} / \mathrm{s}$ for, respectively, implying that the critical speed is actually affected by the geometry of train loading.

\section{Development of sensitivity charts for calculation of critical speed}

It is now useful to synthesise the results of the study into suitable formulations that can be used in practice to determine the critical speed for any train. As concluded in the preceding section, the critical speed is affected by the train loading geometry. Therefore, the results of the study were manipulated to develop a relationship that allows calculation of the critical speed for any train with respect to the critical speed of the X-2000 HST. However, before developing such relationship, the discussion presented below is necessary.

Fig. 12 shows the distance-history of the sleeper displacement at the centre of the track for the X-2000 HST and Thalys HST for the same track-ground condition (Model-3). In this figure, the distance in the $x$-axis coordinate is calculated by multiplying the critical speed $\left(C_{c r}\right)$ of each individual train by the corresponding time of train passage. In Fig. 12a, each deflection peak represents the deflection generated for the X-2000 HST due to the overlap of induced stresses of four wheels of two consecutive bogies. The distance between any two peaks for the X-2000 HST would be equal to the carriage length, $L$, defined earlier or the distance of the centre-to-centre of two consecutive sets of four wheels. So, the load application frequency, or the carriage passing frequency $\left(f_{c}\right)$, at the critical speed of the $\mathrm{X}$ 2000 HST can be computed by dividing the train critical speed by the length of the carriage, $L$; hence, $f_{c}$ for the X-2000 HST would be equal to $7.6 \mathrm{~Hz}$ (i.e. $185 \mathrm{~m} / \mathrm{s}$ divided by $24.4 \mathrm{~m}$ ), which is equivalent to the natural frequency of the track-ground system. On the other hand, each deflection peak for the Thalys HST (Fig. 12b) represents the deflection generated due to 
the overlap of induced stresses of two wheels of one bogie. Thereby, the distance between any two peaks for the Thalys HST would be equal to the carriage length, $L$, or the distance of the centre-to-centre of two consecutive bogies, $L_{b}$. Accordingly, $f_{c}$ of the Thalys HST would be equal to $7.6 \mathrm{~Hz}$ (i.e. $142 \mathrm{~m} / \mathrm{s}$ divided by $18.7 \mathrm{~m}$ ), which is also equivalent to the natural frequency of the track-ground system. The above results show that at the critical speed condition, the load application (or carriage passing) frequency of trains is usually equal to the natural frequency, $f_{n}$, of the track-ground system. This conclusion can be mathematically expressed as follows:

$f_{n}=f_{c(\text { any particular train })}=f_{c(X-2000 H S T)}=f_{c(\text { Thalys }-H S T)}$

By correlating $f_{c}$ of any other particular train, i.e. $f_{c(\text { any } \text { particular train })}$ with respect to $f_{c(X-2000)}$ or $f_{c(\text { Thalys-HST) }}$ and by replacing it with its corresponding critical speed and carriage length, Equation (5) can be rewritten as:

$\frac{C_{c r(\text { particulartrain })}}{L_{\text {particulartrain }}}=\frac{C_{c r(X-2000 H S T)}}{L_{X-2000 H S T}}=\frac{C_{c r(\text { Thalys }-H S T)}}{L_{\text {Thalys-HST }}}$

where; $C_{c r(\text { particulartrain })}, C_{c r(X-2000 H S T)}$ and $C_{c r(T h a l y s-H S T)}$ are the critical speeds of the desired particular train, X-2000 HST and Thalys HST, respectively; and $L_{\text {particulartrain }}, L_{X-2000 H S T}$ and $L_{\text {Thalys-HST }}$ are the carriage lengths of the desired particular train, X-2000 HST and Thalys HST, respectively. By considering the length of the central carriage of the X-2000 HST (i.e. $L_{X-2000 H S T}=24.4 \mathrm{~m}$ ), Equation (6) can be simplified as follows: 
$C_{c r(\text { particular train })}=\frac{C_{c r(X-2000 H S T)}}{24.4} \times L_{\text {particular train }}$

Likewise, by considering the length of the central carriage of the Thalys-HST (i.e. $L_{\text {Thalys }-H S T}$ $=18.7 \mathrm{~m})$, Equation (7) can also be simplified as follows:

$C_{c r(\text { particular train })}=\frac{C_{c r(\text { Thalys- }-H S T)}}{18.7} \times L_{\text {particular train }}$

Equations (7) or (8) can then be used to calculate the critical speed of any train with respect to the critical speed of the X-2000 HST, i.e. $C_{c r(X-2000 H S T)}$, or the critical speed of the Thalys HST, i.e. $C_{c r(T h a l y s-H S T)}$.

As mentioned above, either Equations (7) or (8) can be used to determine the critical speed for any particular train. However, this requires either the critical speed of the X-2000 or Thalys HST to be provided. For this, sensitivity charts were developed using the results obtained from Section 2.2.2 from which the critical speed of the X-2000 HST can be directly obtained using Fig. 13. Similar sensitivity charts for the critical speed of the Thalys HST were not developed as they are not needed because Equation (8) does not have to be used. The essence of the sensitivity charts is to readily determine the critical speed of the X-2000 HST for different track subgrade stiffnesses and thicknesses. One of the sensitivity charts was originally developed based on the deformation modulus of the railway subgrade, $E_{s}$ (Fig. 13a), and another corresponding sensitivity chart was developed based on the subgrade shear wave velocity, $C_{s}$ (Fig. 13b), using the subgrade density, $\rho$, Poisson's ratio, $v$, and the following well-known equation: 


$$
C_{s}=\sqrt{\frac{E}{2 \rho(1+v)}}
$$

\section{Summary and conclusions}

In this paper, an advanced 3D finite element modelling was performed to simulate the dynamic response of ballasted railway tracks subjected to train moving loads, with special reference to the critical speed. The specific modelling methodology successfully predicted the measurements taken from the very well documented case study available in the literature. The obtained results confirmed that the FE modelling is trustworthy and can be used with confidence to simulate the behaviour of railway track foundations, for both the quasi-static and dynamic loading conditions. The encouraging results obtained for the historical case study were used to carry out further analysis in relation to the critical speed under various conditions of the train-track-ground system. The following conclusions are drawn from the current study:

- Due to the nonlinearity of substructure materials, slightly higher downward deflections occur in the nonlinear subgrade track than those of the linear subgrade track. However, the influence of nonlinearity of substructure materials on the critical speed is almost negligible.

- In general, the magnitude of the critical speed is found to be higher than the Rayleigh wave velocity and shear wave velocity of track-ground system.

- The evolution of sleeper deflection with train speed indicates that when the train speed exceeds $75 \%$ of critical speed, the amplitude of dynamic response of the track 
increases rapidly. Therefore, $75 \%$ of critical speed can be assumed as the practical speed limit of ballasted railway tracks.

- The subgrade stiffness and thickness were found to have significant influences on the dynamic amplification factor (DAF) and critical speed of the train-track-ground system. The DAF was found to decrease with the increase of both the subgrade stiffness and thickness. On the other hand, the magnitude of critical speed was found to increase with the increase in the subgrade stiffness, while it decreases with the increase in the subgrade thickness.

- The critical speed of the track-ground system is independent of the train loading amplitude; however, it is significantly influenced by the train loading geometry.

- At the critical speed condition, the carriage passing frequency of any particular train is equal to the natural frequency of the track-ground system.

\section{References}

Al-Shayea N, Abduljauwad S, Bashir R, Al-Ghamedy H, Asi I. Determination of parameters for a hyperbolic model of soils. In: Proceedings of the ICE-Geotechnical Engineering 149; 2003. p. 105-17.

Alves Costa P, Colaço A, Calçada R, Cardoso AS. Critical speed of railway tracks. Detailed and simplified approaches. Transportation Geotechnics 2015;2:30-46.

Anderson WF, Fair P. Behavior of railroad ballast under monotonic and cyclic loading. J Geotech Geoenviron Eng 2008;134(3):316-27.

Araújo NMF. High-speed trains on ballasted railway track: dynamic stress field analysis [Doctoral Thesis]: Universidade do Minho, 2011.

Auersch L. The effect of critically moving loads on the vibrations of soft soils and isolated railway tracks. J Sound Vib 2008;310(3):587-607.

Bian X, Chen Y. An explicit time domain solution for ground stratum response to harmonic moving load. Acta Mech Sin 2006;22(5):469-78. 
Bian X, Cheng C, Jiang J, Chen R, Chen Y. Numerical analysis of soil vibrations due to trains moving at critical speed. Acta Geotechnica 2014:1-14.

Chowdhury I, Dasgupta SP. Computation of Rayleigh damping coefficients for large systems. EJGE 2003;8:1-11.

Cunha J, Correia AG. Evaluation of a linear elastic 3D FEM to simulate rail track response under a high-speed train. In: Miura et al., editors. ICTG - Advances in Transportation Geotechnics II. London: Taylor \& Francis - Balkema, 2012. p. 196-201.

Degrande G, Schillemans L. Free field vibrations during the passage of a Thalys high-speed train at variable speed. J Sound Vib 2001;247(1):131-44.

Duncan JM, Byrne P, Wong KS, Mabry P. Strength, stress-strain and bulk modulus parameters for finite element analyses of stresses and movements in soil masses. In: Geotechnical Engineering, University of California, Report No. UCB/GT/80-01, 1980.

Duncan JM, Chang C-Y. Nonlinear analysis of stress and strain in soils. J Soil Mech and Found Div 1970;96(5):1629-53.

Galavi V, Brinkgreve RBJ. Finite element modelling of geotechnical structures subjected to moving loads. In: Hicks et al., editors. VIII ECNUMGE - Numerical Methods in Geotechnical Engineering. Delft, Netherlands: Taylor and Francis - Balkema, 2014. p. 23540.

Grundmann H, Lieb M, Trommer E. Response of a layered half-space to traffic loads moving along its surface. Arch Appl Mech 1999;69(1):55-67.

Hall L. Simulations and analyses of train-induced ground vibrations: a comparative study of two- and three-dimensional calculations with actual measurements. [Doctoral Thesis]: Royal Institute of Technology, 2000.

Hall L. Simulations and analyses of train-induced ground vibrations in finite element models. Soil Dyn Earthqu Eng 2003;23(5):403-13.

Kaynia AM, Madshus C, Zackrisson P. Ground vibration from high-speed trains: prediction and countermeasure. J Geotech Geoenviron Eng 2000;126(6):531-37.

Kouroussis G, Verlinden O, Conti C. Ground propagation of vibrations from railway vehicles using a finite/infinite-element model of the soil. J Rail Rapid Transit 2009;223(4):405-13.

Kouroussis G, Verlinden O, Conti C. Finite-dynamic model for infinite media: corrected solution of viscous boundary efficiency. J Eng Mech 2011;137(7):509-11.

Krylov VV. On the theory of railway-induced ground vibrations. J Phy 1994;4(C5):769-72.

Krylov VV. Noise and vibration from high-speed trains. London: Thomas Telford; 2001.

Lysmer J, Kuhlemeyer RL. Finite dynamic model for infinite media. ASCE, J Soil Mech Found Div 1969;95(EM4):859-77. 
Madshus C, Kaynia AM. Dynamic ground interaction; a critical issue for high speed train lines on soft soil. In: Barends et al., editors. Geotechnical engineering for transportation infrastructure. Amsterdam, Netherlands: Balkema, 1999. p. 1-8.

Madshus C, Kaynia AM. High-speed railway lines on soft ground: dynamic behaviour at critical train speed. J Sound Vib 2000;231(3):689-701.

MIDAS IT. Co. Ltd. Manual of GTS-NX 2013 v1.2: new experience of geotechnical analysis system. MIDAS Company Limited, South Korea, 2013.

Powrie W, Priest JA, Clayton CRI. Recent research on railway track sub-base behaviour. In: Ellis Y, McDowell, Dawson \& Thom, editors. Advances in Transportation Geotechnics: Proceedings of the 1st International Conference on Transportation Geotechnics. London, UK: Taylor \& Francis Group, 2008. p. 37-46.

Powrie W, Yang LA, Clayton CRI. Stress changes in the ground below ballasted railway track during train passage. Journal of rail and rapid transit 2007;221(2):247-61.

Priest JA, Powrie W. Determination of dynamic track modulus from measurement of track velocity during train passage. J Geotech Geoenviron Eng 2009;135(11):1732-40.

Sheng X, Jones CJC, Thompson DJ. A theoretical study on the influence of the track on traininduced ground vibration. J Sound Vib 2004;272(3):909-36.

Takemiya H. Simulation of track-ground vibrations due to a high-speed train: the case of X2000 at Ledsgard. J Sound Vib 2003;261(3):503-26.

Wanming Z, Zhenxing H, Xiaolin S. Prediction of high-speed train induced ground vibration based on train-track-ground system model. Earthqu Eng Eng Vib 2010;9(4):545-54.

Wener-Fligner Z. A new Japanese train has broken the world speed record twice this week. QUARTZ, April 21, 2015.

Woldringh RF, New BM. Embankment design for high speed trains on soft soils. In: Barends et al., editors. Geotechnical engineering for transportation infrastructure. Amsterdam: Balkema, 1999. p. 1-10.

Yang L, Powrie W, Priest JA. Dynamic stress analysis of a ballasted railway track bed during train passage. J Geotech Geoenviron Eng 2009;135(5):680-89. 


\section{List of Tables}

Table 1

Material properties of the X-2000 HST track at the Ledsgard site (Hall, 2000).

Table 2

Geometry and axle loads of the X-2000 HST (Takemiya, 2003).

Table 3

Material constitutive model used to investigate the impact of nonlinearity of track materials on the critical speed.

Table 4

Properties used to investigate the impact of nonlinearity of track materials on the critical speed.

\section{Table 5}

Geometry and load characteristics of the Thalys HST (Cunha and Correia, 2012). 
Table 1

Material properties of the X-2000 HST track at the Ledsgard site (Hall, 2000).

\begin{tabular}{|c|c|c|c|c|c|c|c|}
\hline Materials & $\begin{array}{l}\text { Shear wave } \\
\text { veloocy, } \\
C_{s} \\
(\mathrm{~m} / \mathrm{s})\end{array}$ & $\begin{array}{l}\text { Dynamic } \\
\text { Young's } \\
\text { modulus, } \\
E \\
(\mathrm{MPa})\end{array}$ & $\begin{array}{l}\text { Poisson's } \\
\text { ration, } \\
v\end{array}$ & $\begin{array}{l}\text { Unit } \\
\text { weight, } \\
\gamma \\
\left(\mathrm{kN} / \mathrm{m}^{3}\right)\end{array}$ & $\begin{array}{l}\text { Cohesion, } \\
c \\
(\mathrm{kPa})\end{array}$ & $\begin{array}{l}\text { Friction } \\
\text { angle, } \\
\phi^{\circ}\end{array}$ & $\begin{array}{l}\text { Damping } \\
\text { ratio, } \\
\xi\end{array}$ \\
\hline Rail & - & 210000 & 0.30 & 76.50 & - & - & - \\
\hline Sleeper & - & 30000 & 0.20 & 20.15 & - & - & 0.02 \\
\hline Ballast \#1 & 165 & 134.50 & 0.30 & 18.64 & 0 & 50 & 0.03 \\
\hline Ballast \#2 & 165 & 134.50 & 0.30 & 18.64 & 0 & 50 & 0.03 \\
\hline Interface & 45 & 10.00 & 0.48 & 16.67 & 0 & 30 & 0.06 \\
\hline Crust & 60 & 18.00 & 0.48 & 16.67 & - & - & 0.06 \\
\hline Peat \#1 & 26 & 2.55 & 0.49 & 12.36 & - & - & 0.06 \\
\hline Peat \#2 & 44 & 7.30 & 0.49 & 12.36 & - & - & 0.06 \\
\hline Clay \#1 & 49 & 10.50 & 0.49 & 14.22 & - & - & 0.09 \\
\hline Clay \#2 & 56 & 13.60 & 0.49 & 14.22 & - & - & 0.09 \\
\hline Clay \#3 & 75 & 25.26 & 0.49 & 14.72 & _- & _- & 0.09 \\
\hline
\end{tabular}

Note: dash (-) indicates "not applicable" 
Table 2

Geometry and axle loads of the X-2000 HST (Takemiya, 2003).

\begin{tabular}{lllllll}
\hline Car number, & \multicolumn{2}{l}{ Spacing } & & & \multicolumn{2}{c}{ Standard axle load } \\
\cline { 2 - 3 }$n$ & $a(\mathrm{~m})$ & $b(\mathrm{~m})$ & & & $P_{1}$ & $P_{2}$ \\
\hline 1 & 2.9 & 11.6 & 22.2 & & 162.0 & 122.5 \\
2 & 2.9 & 14.8 & 24.4 & & 122.5 & 122.5 \\
3 & 2.9 & 14.8 & 24.4 & & 122.5 & 122.5 \\
4 & 2.9 & 14.8 & 24.4 & & 122.5 & 122.5 \\
5 & 2.9 & 6.6 & 17.2 & & 180.0 & 180.0 \\
\hline
\end{tabular}


Table 3

Material constitutive model used to investigate the impact of nonlinearity of track materials on the critical speed.

\begin{tabular}{llll}
\hline Railway track model & Subgrade & Material model & \\
\cline { 3 - 4 } & type & Ballast & Subgrade \\
\hline Model-1 & Soft (Fat Clay) & LE & LE \\
Model -2 & Soft (Fat Clay) & MC & DC \\
Model-3 & Stiff (Low density sand) & LE & LE \\
Model-4 & Stiff (Low density sand) & MC & DC \\
\hline
\end{tabular}


Table 4

Properties used to investigate the impact of nonlinearity of track materials on the critical speed.

\begin{tabular}{|c|c|c|c|c|c|c|c|c|c|c|}
\hline \multirow[t]{2}{*}{ Material type } & \multirow{2}{*}{$\begin{array}{l}\text { Unit } \\
\text { weight, } \gamma \\
\left(\mathrm{kN} / \mathrm{m}^{3}\right)\end{array}$} & \multicolumn{2}{|c|}{ Elastic properties } & \multicolumn{2}{|c|}{ Plastic properties } & \multicolumn{3}{|c|}{ DC nonlinearity properties } & \multicolumn{2}{|c|}{ Dynamic properties } \\
\hline & & $\begin{array}{l}\text { Young's } \\
\text { modulus, } E \\
(\mathrm{MPa})\end{array}$ & $\begin{array}{l}\text { Poisson's } \\
\text { ratio, } \\
v\end{array}$ & $\begin{array}{l}\text { Cohesion, } \\
c \\
(\mathrm{kPa})\end{array}$ & $\begin{array}{l}\text { Friction } \\
\text { angle, } \\
\phi^{\mathrm{o}}\end{array}$ & $\begin{array}{l}\text { Modulus } \\
\text { number, } K\end{array}$ & $\begin{array}{l}\text { Modulus } \\
\text { exponent, } n\end{array}$ & $\begin{array}{l}\text { Failure } \\
\text { ratio, } \\
R_{f}\end{array}$ & $\begin{array}{l}\text { Shear wave } \\
\text { velocity, } \\
C_{s} \\
(\mathrm{~m} / \mathrm{s})\end{array}$ & $\begin{array}{l}\text { Rayleigh wave } \\
\text { velocity, } \\
C_{R} \\
(\mathrm{~m} / \mathrm{s})\end{array}$ \\
\hline Ballast & 18.6 & 200 & 0.30 & 0.0 & 50 & - & - & - & 201 & 187 \\
\hline Soft subgrade & 15.4 & 6.9 & 0.38 & 67.6 & 0.0 & 65 & 0.14 & 0.77 & 40 & 37 \\
\hline Stiff subgrade & 15.6 & 58.5 & 0.35 & 0.0 & 38 & 586 & 1.07 & 0.90 & 117 & 109 \\
\hline
\end{tabular}


Table 5

Geometry and load characteristics of the Thalys HST (Cunha and Correia 2012).

\begin{tabular}{lcccccc}
\hline $\begin{array}{l}\text { Carriage } \\
\text { name }\end{array}$ & $\begin{array}{c}\text { Carriage } \\
\text { number }\end{array}$ & $\begin{array}{c}\text { Axles per } \\
\text { carriage }\end{array}$ & $\begin{array}{c}L \\
(\mathrm{~m})\end{array}$ & $\begin{array}{c}L_{b} \\
(\mathrm{~m})\end{array}$ & $\begin{array}{c}L_{a} \\
(\mathrm{~m})\end{array}$ & $\begin{array}{c}W_{t} \\
(\mathrm{kN})\end{array}$ \\
\hline Locomotive & 2 & 4 & 22.15 & 14.00 & 3.00 & 168 \\
Side carriage & 2 & 3 & 21.84 & 18.70 & 3.00 & 143 \\
Central carriage & 6 & 2 & 18.70 & 18.70 & 3.00 & 168 \\
\hline
\end{tabular}




\section{Figure captions:}

Fig. 1. The X-2000 HST railway track at the Ledsgard site (Hall, 2000): (a) track geometry and soil profile; and (b) track FE model.

Fig. 2. Schematic diagram of modelled trains: (a) The X-2000 HST (Takemiya, 2003); and (b) The Thalys HST (Degrande and Schillemans, 2001).

Fig. 3. Simulation of moving loads (Araújo, 2011).

Fig. 4. Comparison between FE predicted versus field measured deflection responses at the track centre for: (a) train speed of $70 \mathrm{~km} / \mathrm{h}$; (b) train speed of $200 \mathrm{~km} / \mathrm{h}$; and (c) train speed of $252 \mathrm{~km} / \mathrm{h}$.

Fig. 5. Comparison between FE predicted versus field measured deflection responses based on frequency domain at the track centre for: (a) train speed of $70 \mathrm{~km} / \mathrm{h}$; (b) train speed of 200 $\mathrm{km} / \mathrm{h}$; and (c) train speed of $252 \mathrm{~km} / \mathrm{h}$.

Fig. 6. Track geometry used to investigate the critical speed of train-track-ground system (not to scale).

Fig. 7. Evolution of sleeper deflection versus train speed for: (a) soft subgrade (Model 1 versus Model 2); and (b) stiff subgrade (Model 3 versus Model 4), to investigate the impact of nonlinearity of track materials on the critical speed.

Fig. 8. Typical contour plots of vertical track deflection for: (a) train speed of $50 \mathrm{~m} / \mathrm{s}$; and (b) train speed of $185 \mathrm{~m} / \mathrm{s}$.

Fig. 9. Evolution of dynamic amplification factor (DAF) of sleeper downward deflection versus train speed for different: (a) subgrade stiffnesses; and (b) subgrade thicknesses (where $C_{R}$ is the Raleigh wave velocity of top subgrade soil).

Fig. 10. Evolution of sleeper downward deflection with train speed for three different loading amplitudes.

Fig. 11. Evolution of dynamic amplification factor (DAF) of sleeper downward deflection with train speed for two trains of different geometry.

Fig. 12. Distance-history of sleeper vertical deflection at the critical speeds for the X-2000 HST (upper) and Thalys HST (lower).

Fig. 13. Sensitivity charts to calculate the critical speed of the X-2000 HST for different ground conditions: (a) elastic modulus; and (b) shear wave velocity. 


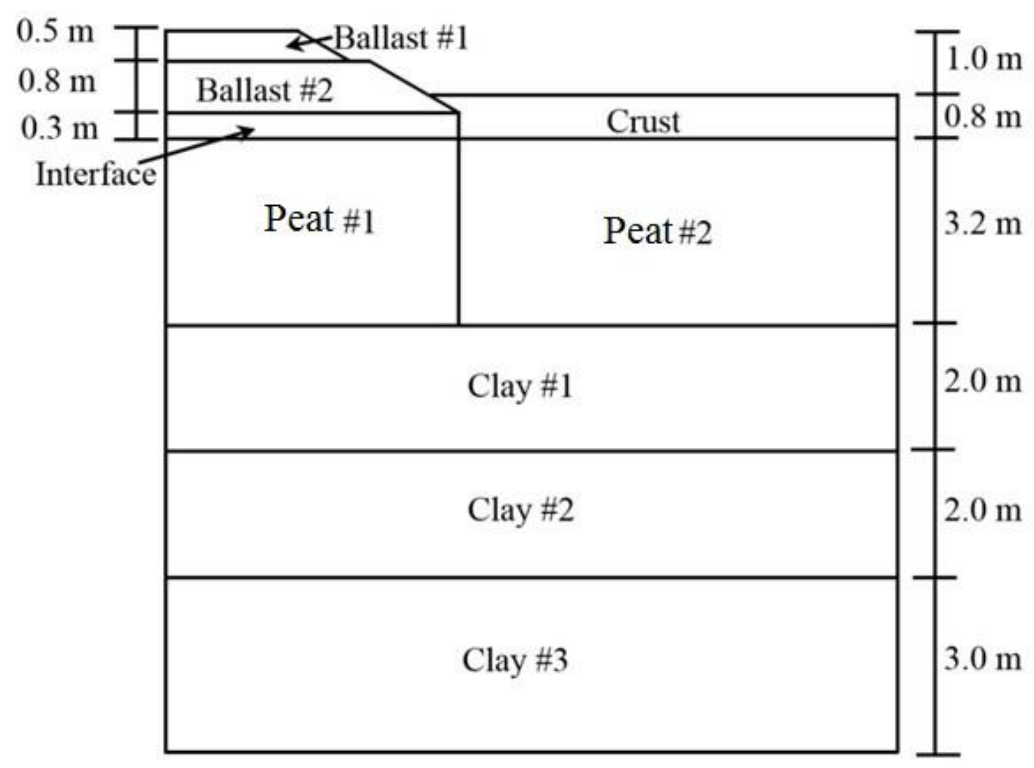

(a)

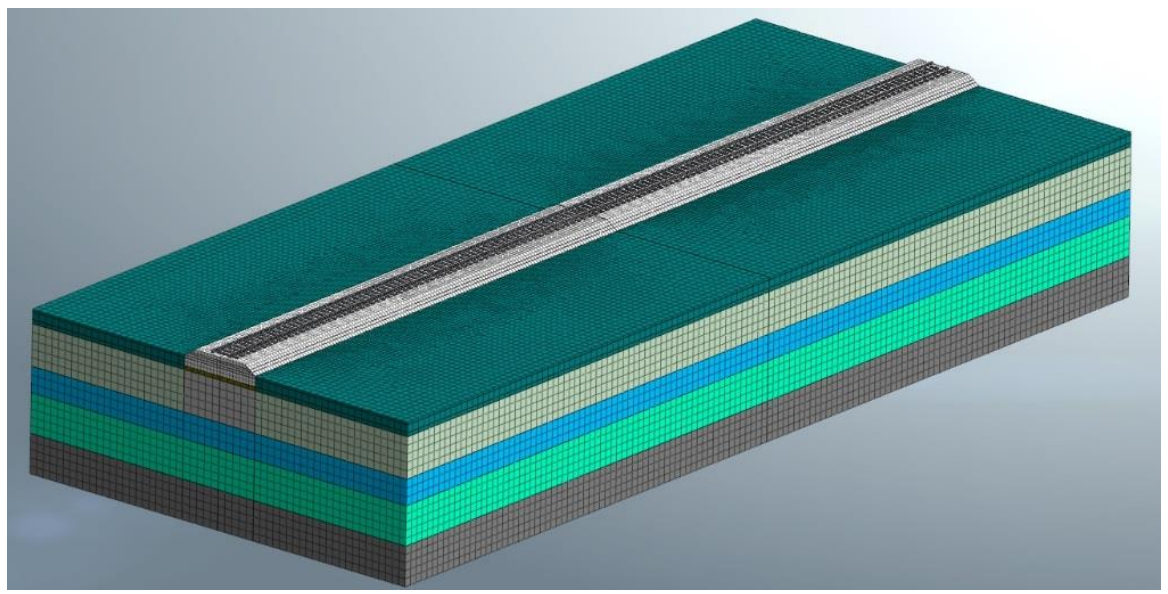

(b)

Fig. 1. The X-2000 HST railway track at the Ledsgard site (Hall 2000): (a) track geometry and soil profile; and (b) track FE model. 

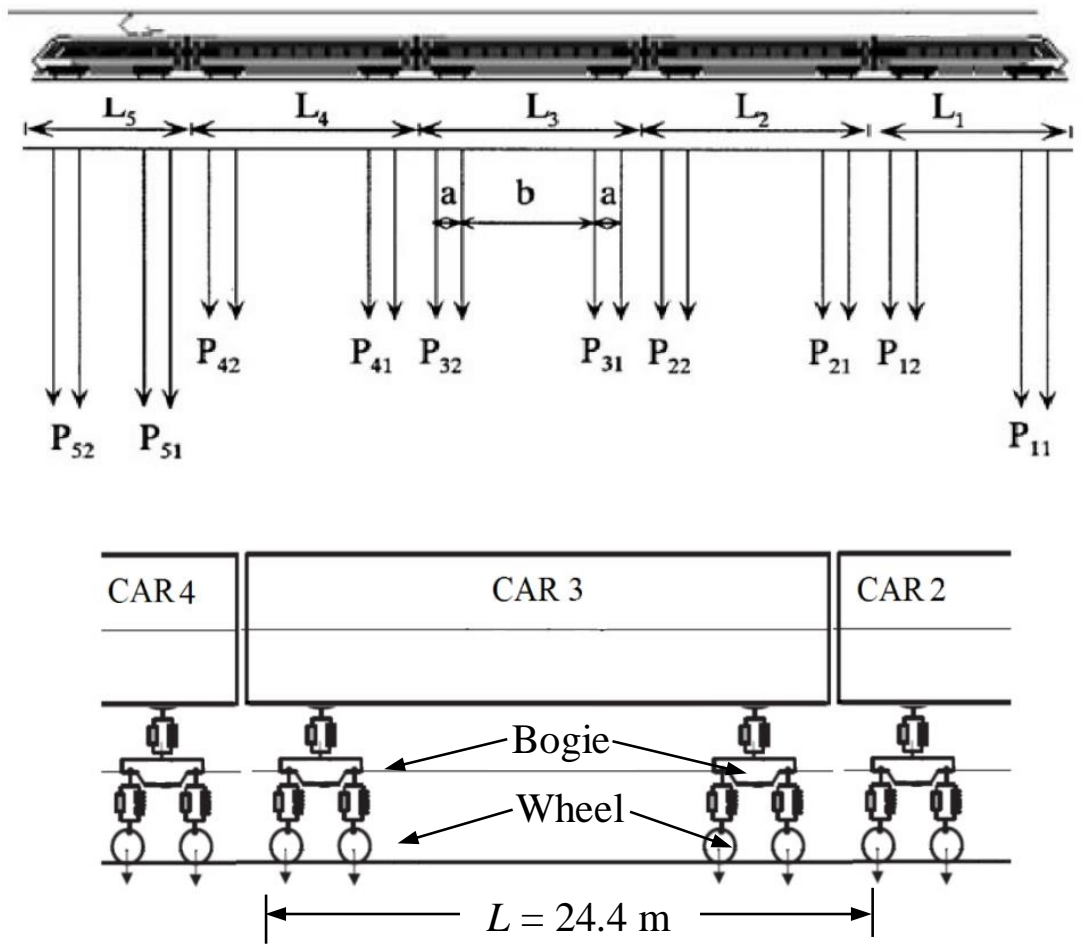

(a) The X-2000 HST

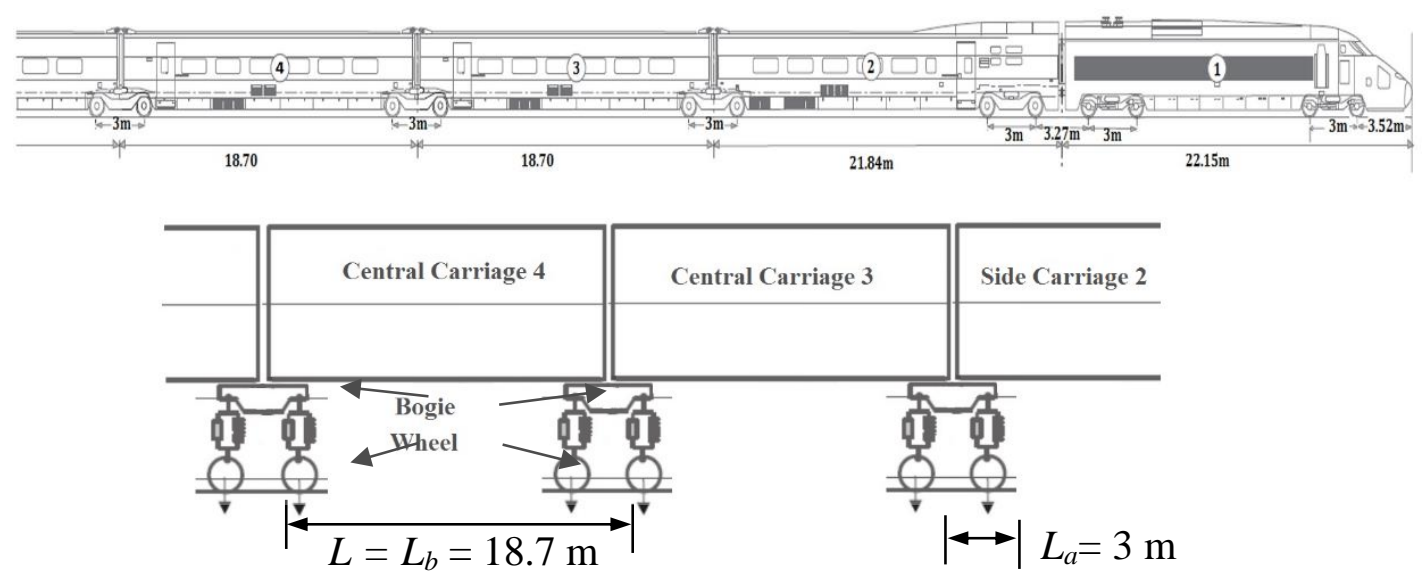

(b) The Thalys HST

Fig. 2. Schematic diagram of modelled trains: (a) The X-2000 HST (Takemiya, 2003); and (b) The Thalys HST (Degrande and Schillemans, 2001). 


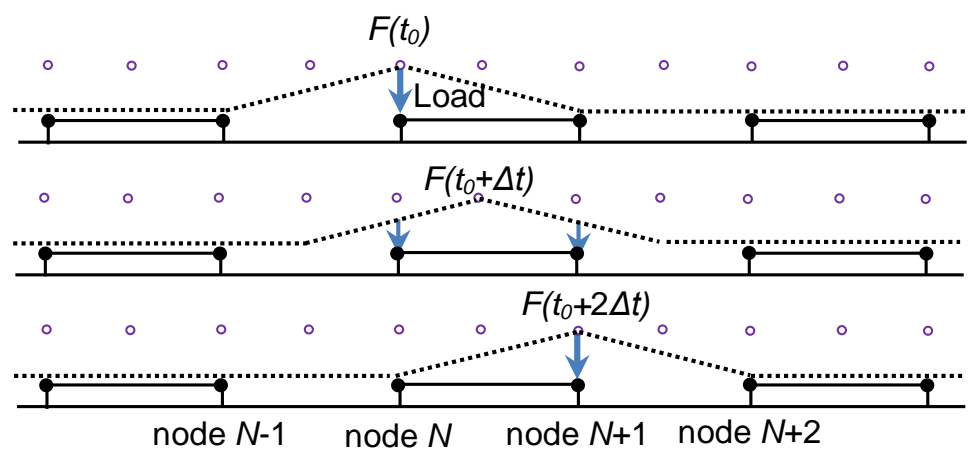

Fig. 3. Simulation of moving loads (Araújo, 2011). 

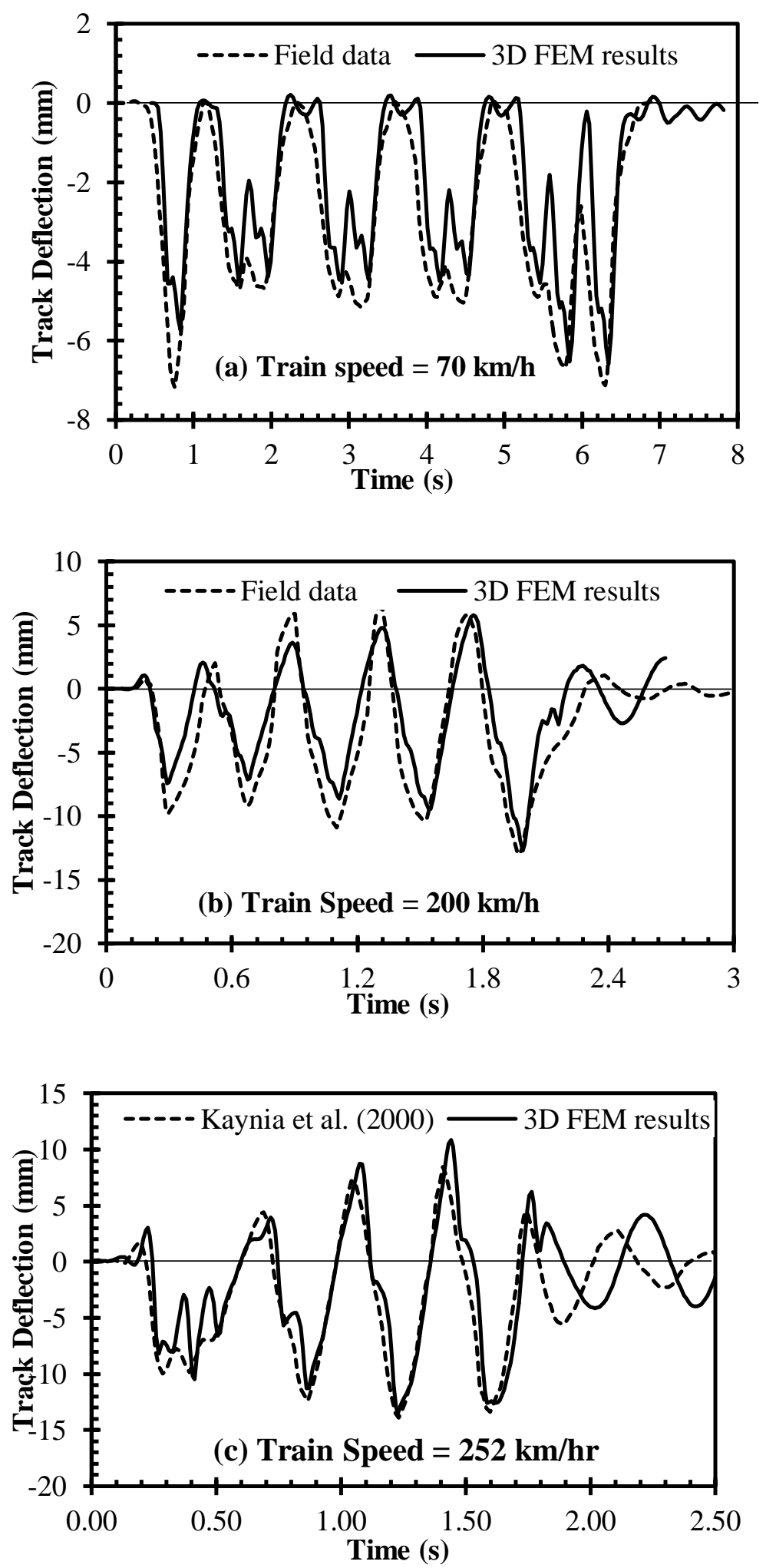

Fig. 4. Comparison between FE predicted versus field measured deflection responses at the track centre for: (a) train speed of $70 \mathrm{~km} / \mathrm{h}$; (b) train speed of $200 \mathrm{~km} / \mathrm{h}$; and (c) train speed of $252 \mathrm{~km} / \mathrm{h}$. 

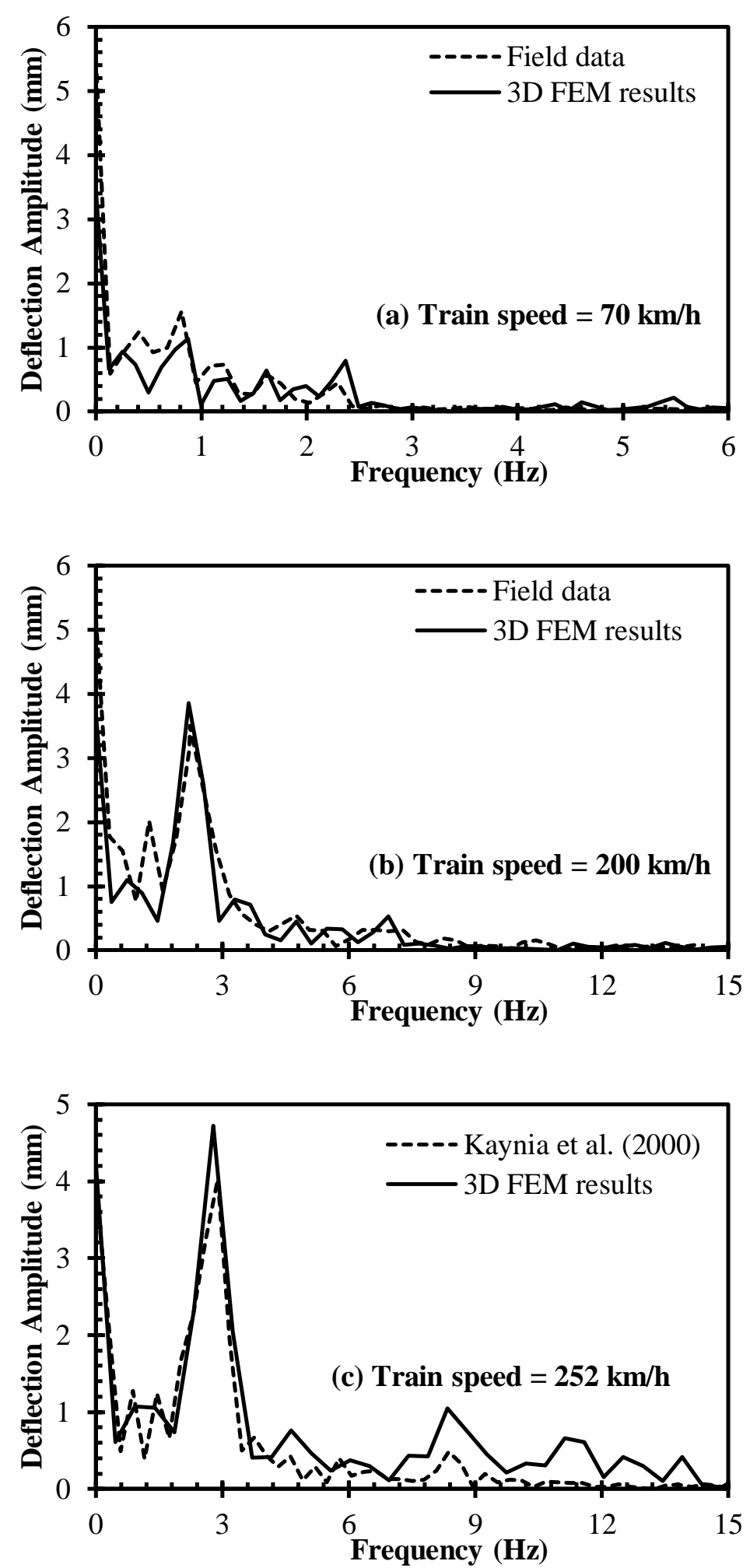

Fig. 5. Comparison between FE predicted versus field measured deflection responses based on frequency domain at the track centre for: (a) train speed of $70 \mathrm{~km} / \mathrm{h}$; (b) train speed of 200 $\mathrm{km} / \mathrm{h}$; and (c) train speed of $252 \mathrm{~km} / \mathrm{h}$. 


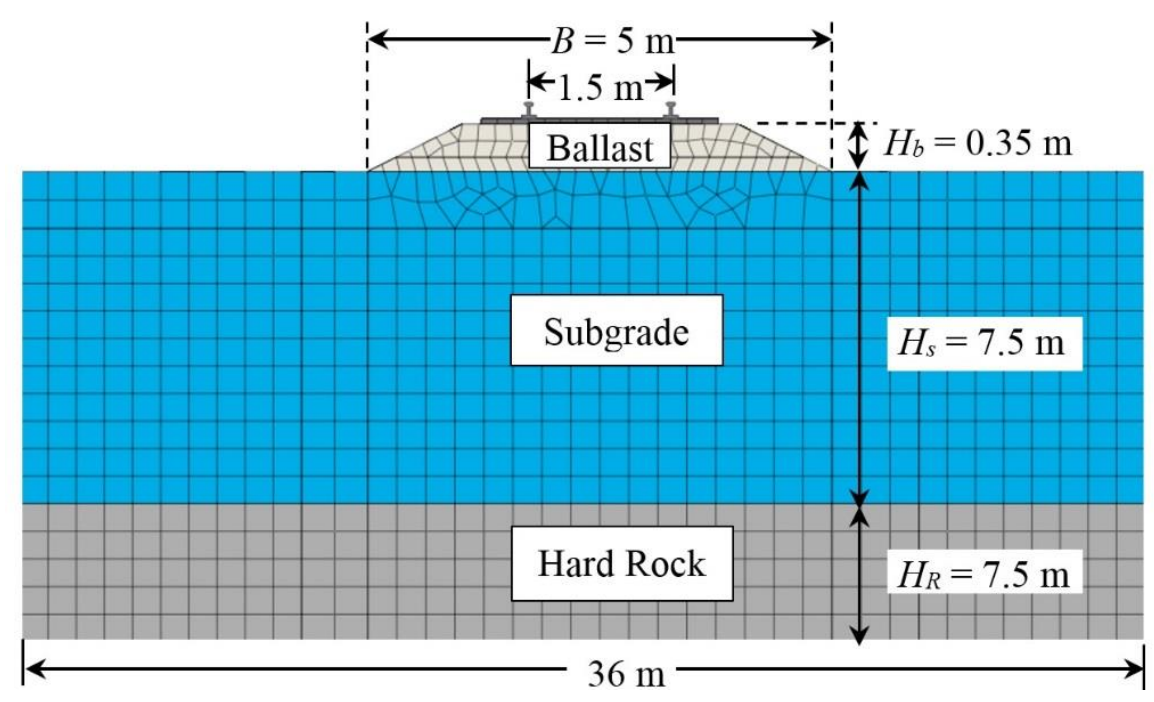

Fig. 6. Track geometry used to investigate the critical speed of train-track-ground system (not to scale). 

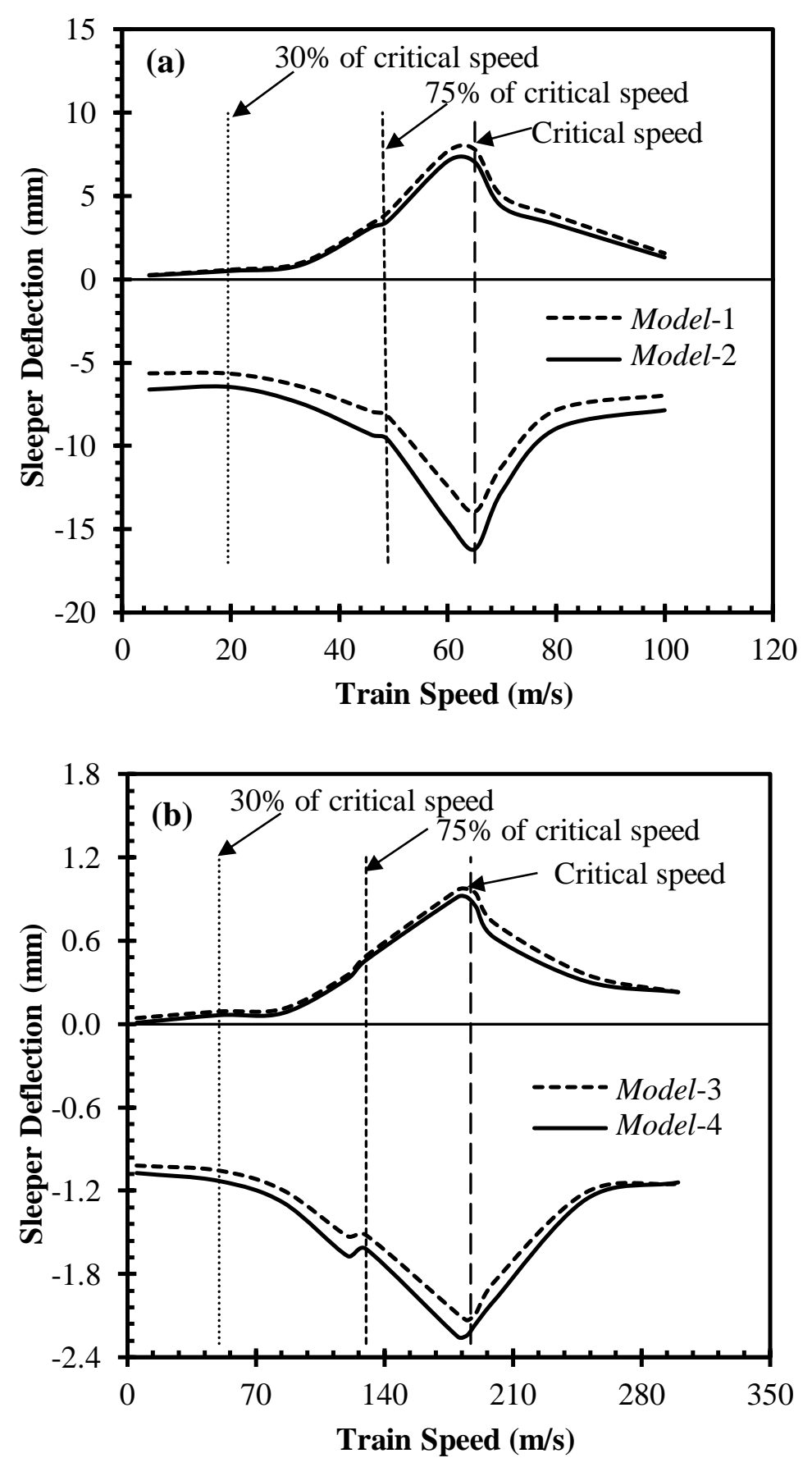

Fig. 7. Evolution of sleeper deflection versus train speed for: (a) soft subgrade (Model 1 versus Model 2); and (b) stiff subgrade (Model 3 versus Model 4), to investigate the impact of nonlinearity of track materials on the critical speed. 

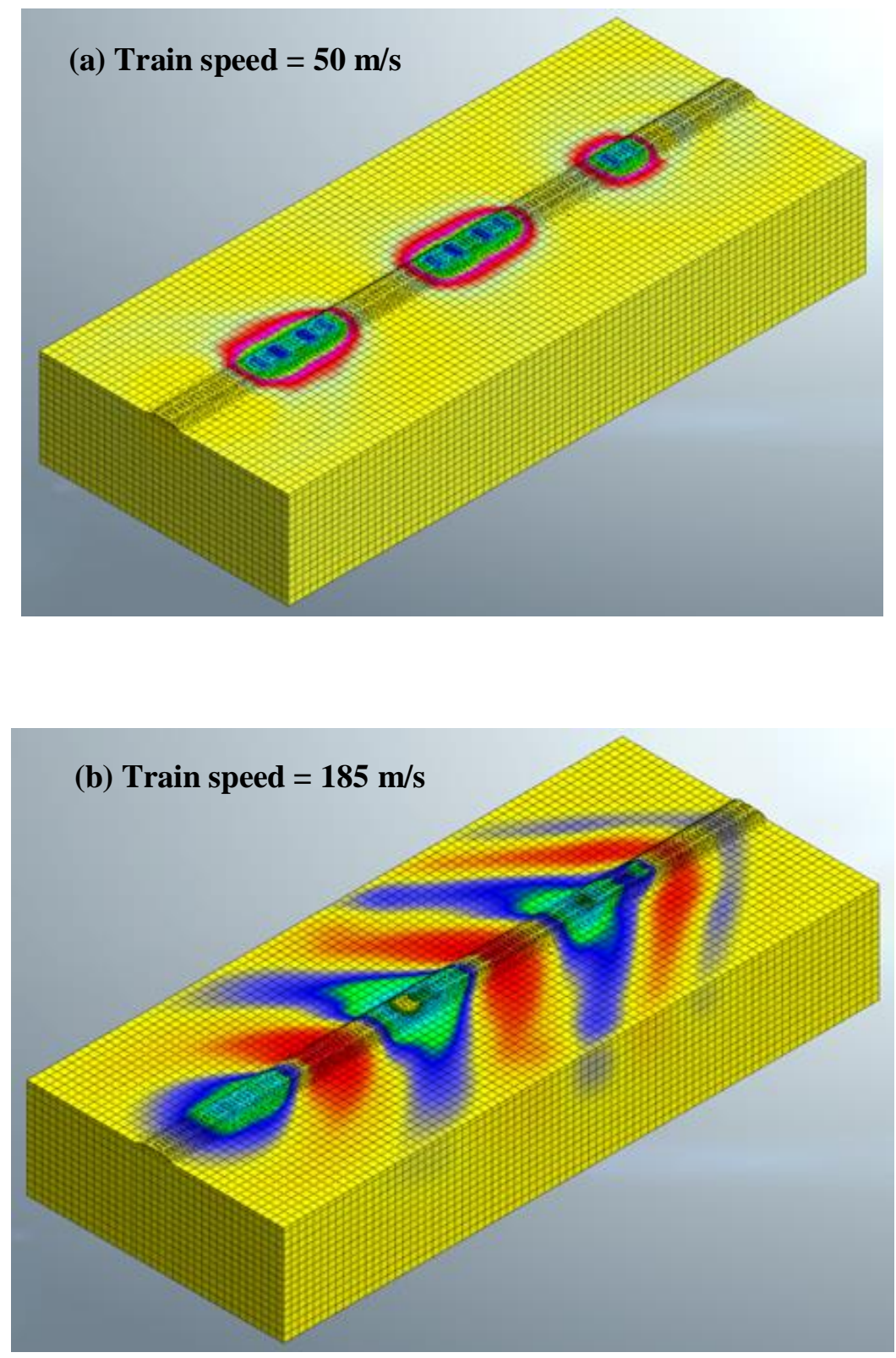

Fig. 8. Typical contour plots of vertical track deflection for: (a) train speed of $50 \mathrm{~m} / \mathrm{s}$; and (b) train speed of $185 \mathrm{~m} / \mathrm{s}$. 

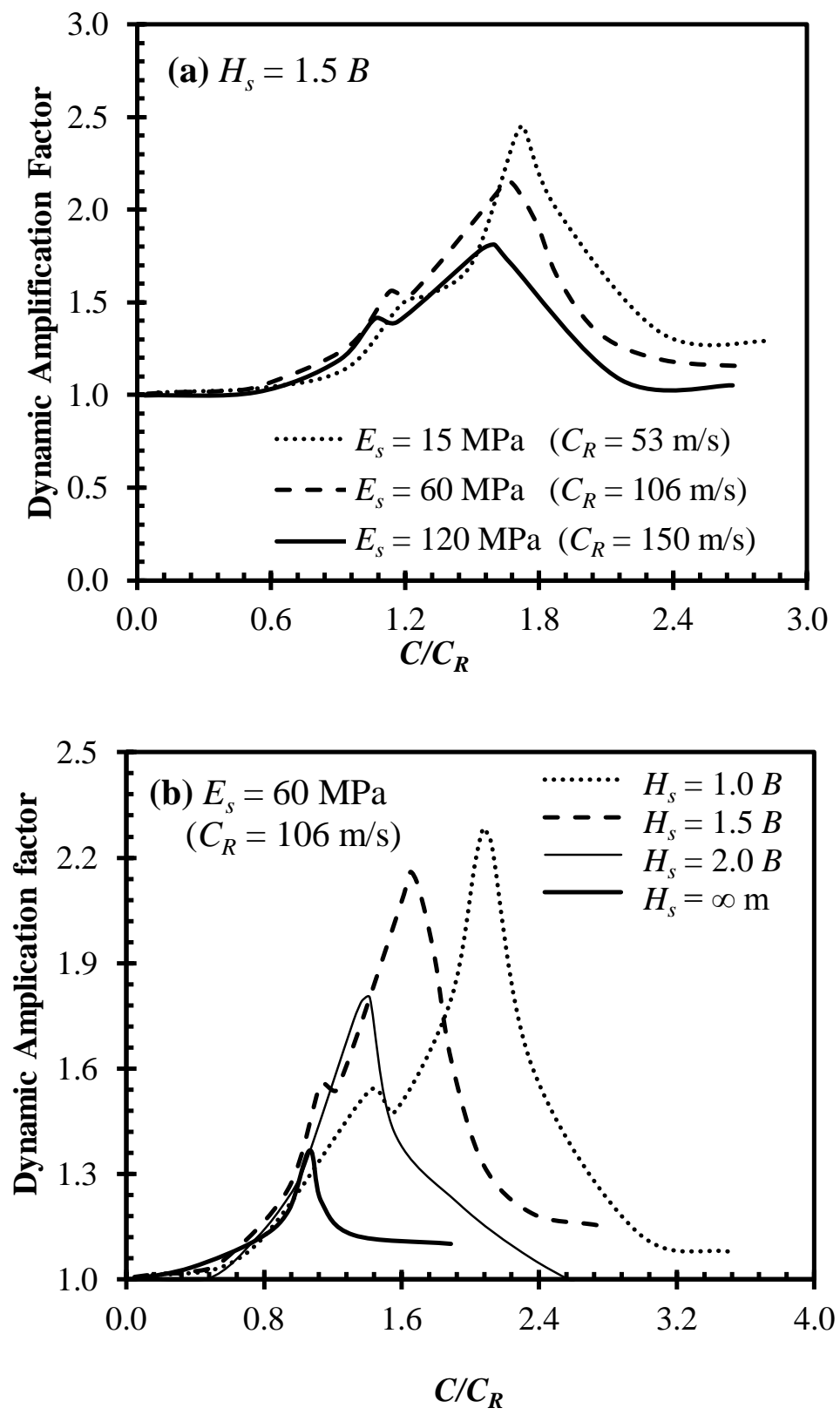

Fig. 9. Evolution of dynamic amplification factor (DAF) of sleeper downward deflection versus normalized train speed $\left(C / C_{R}\right)$ for different: (a) subgrade stiffnesses; and (b) subgrade thicknesses (where $C_{R}$ is the Raleigh wave velocity of top subgrade soil). 


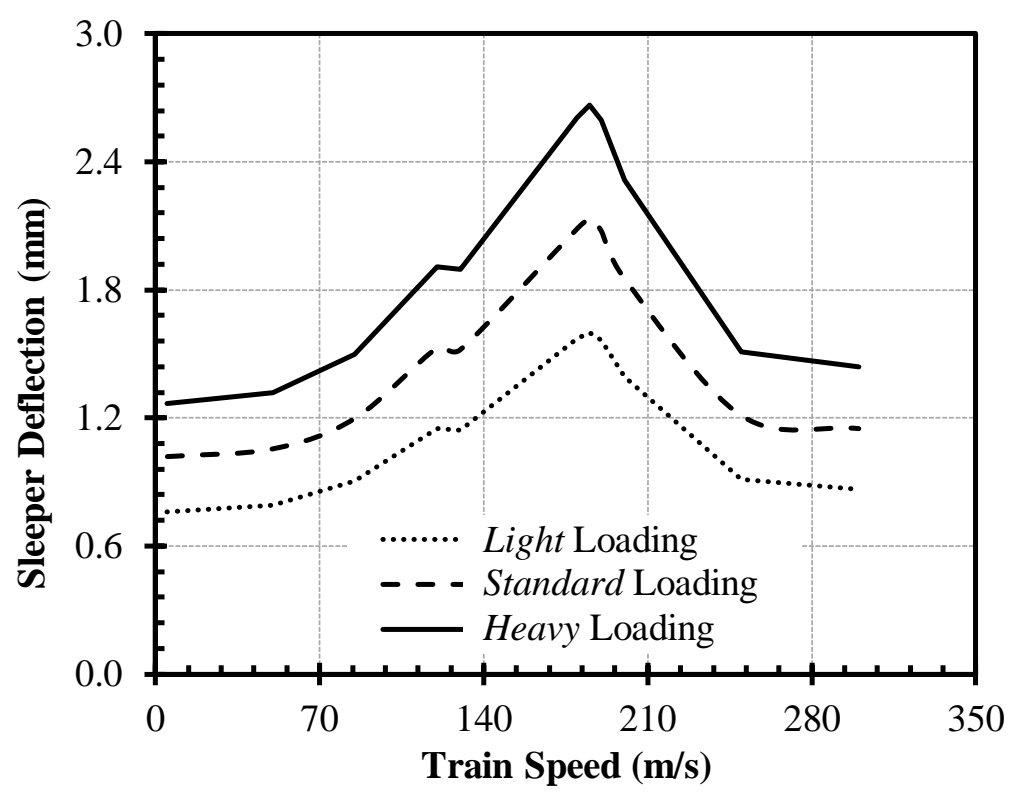

Fig. 10. Evolution of sleeper downward deflection with train speed for three different loading amplitudes. 


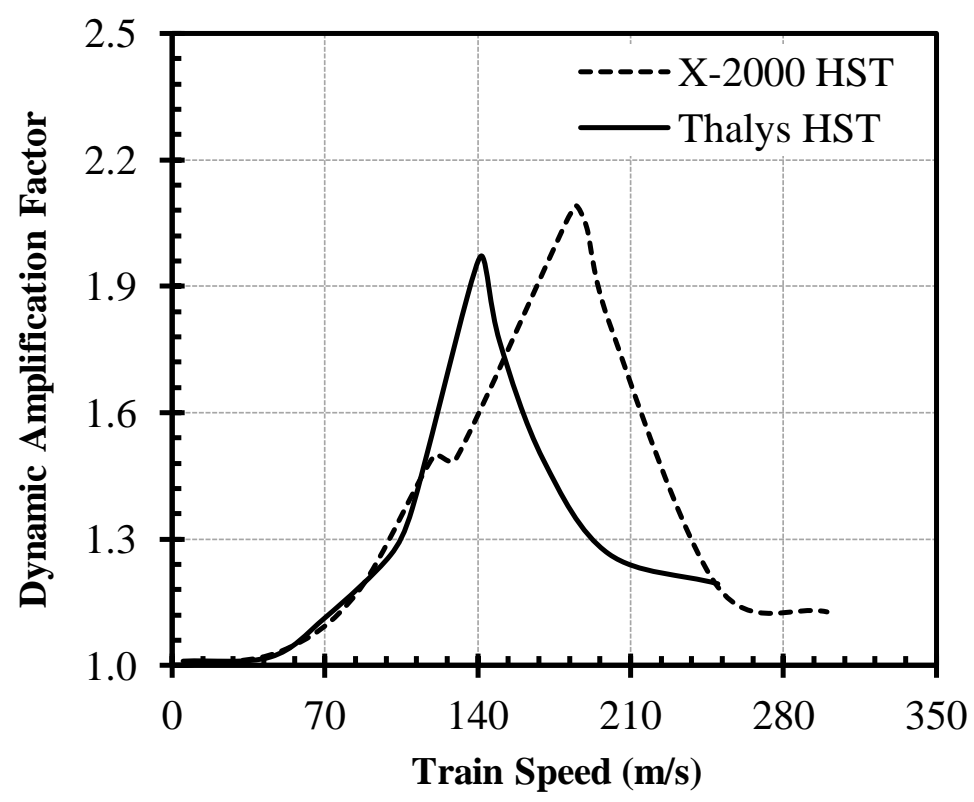

Fig. 11. Evolution of dynamic amplification factor (DAF) of sleeper downward deflection with train speed for two trains of different geometry. 

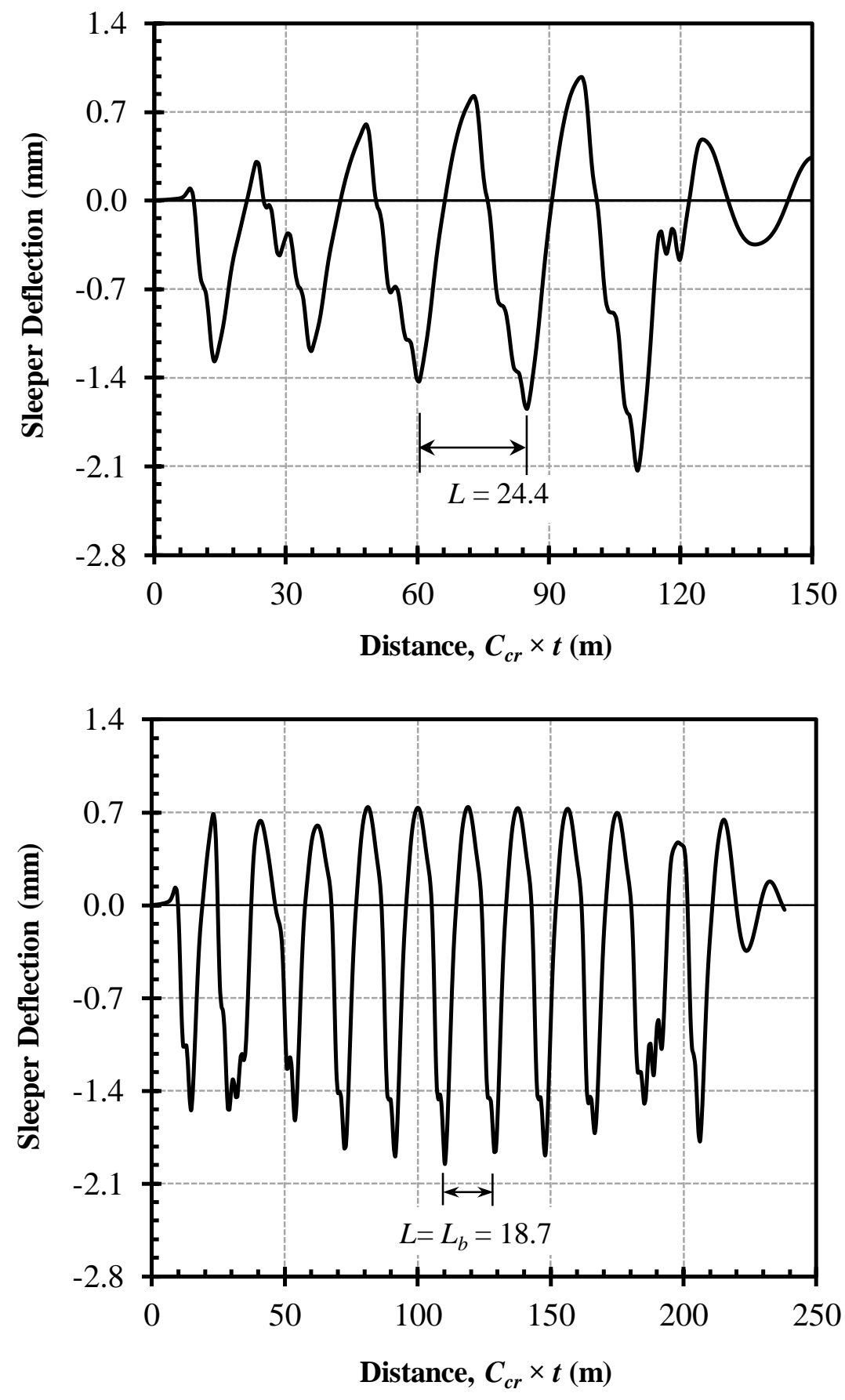

Fig. 12. Distance-history of sleeper vertical deflection at the critical speeds for the X-2000 HST (upper) and Thalys HST (lower). 

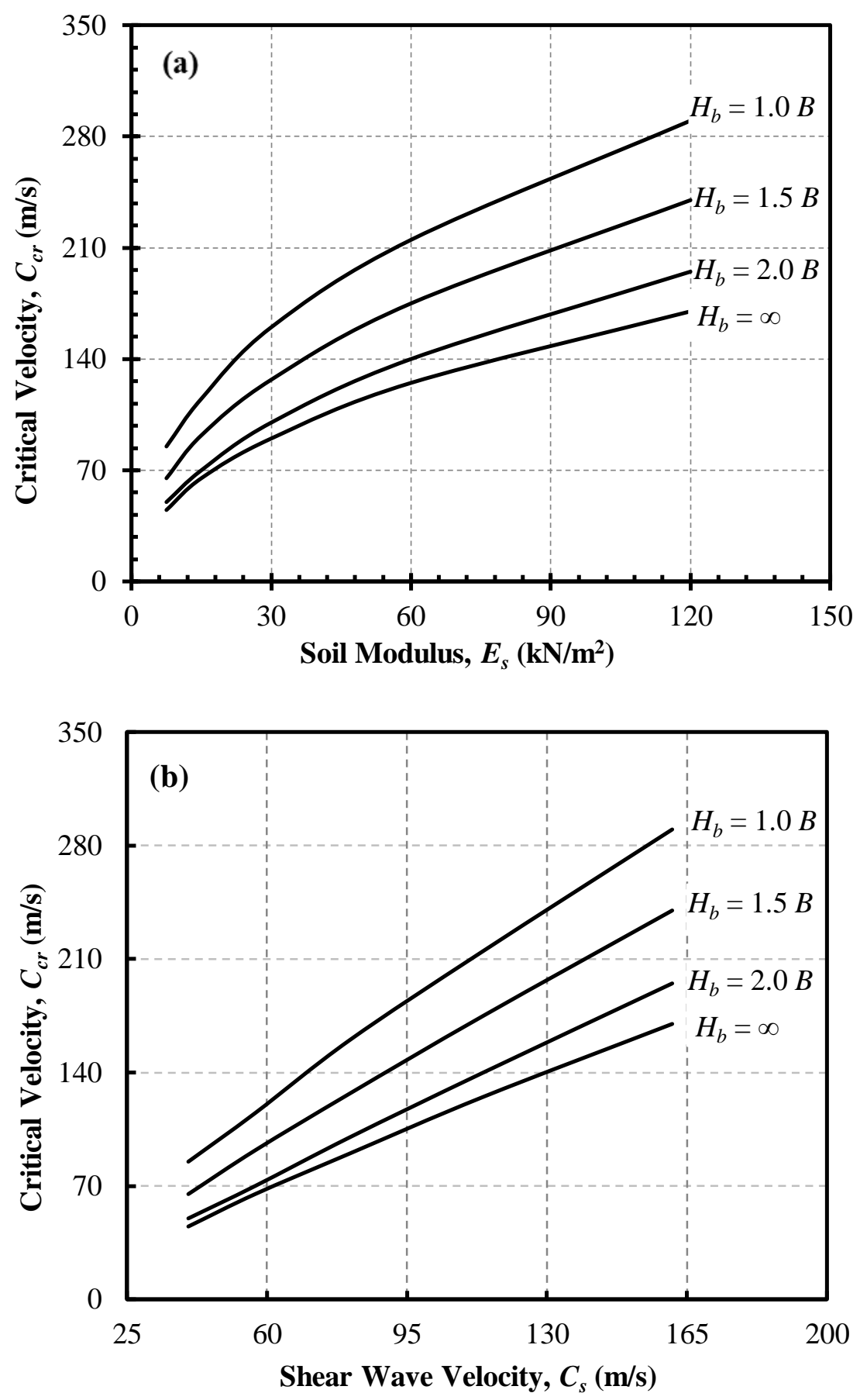

Fig. 13. Sensitivity charts to calculate the critical speed of the X-2000 HST for different ground conditions: (a) elastic modulus; and (b) shear wave velocity. 